\title{
Paideusis
}

\section{Eamonn Callan's Creating Citizens: Political Education and Liberal Democracy}

\section{Paul F. Bitting}

Volume 13, Number 1, 2000

URI: https://id.erudit.org/iderudit/1073021ar

DOI: https://doi.org/10.7202/1073021ar

See table of contents

Publisher(s)

Canadian Philosophy of Education Society

ISSN

0838-4517 (print)

1916-0348 (digital)

Explore this journal

Cite this article

Bitting, P. (2000). Eamonn Callan's Creating Citizens: Political Education and Liberal Democracy. Paideusis, 13(1), 49-54. https://doi.org/10.7202/1073021ar viewed online.

https://apropos.erudit.org/en/users/policy-on-use/ 


\section{Eamonn Callan's Creating Citizens: Political Education and Liberal Democracy}

\section{Paul F. Bitting, North Carolina State University}

North America is defined as a unity and diversity. A unity in terms of one indivisible nation, with liberty and justice for all; and a diversity in terms of being populated by varied cultures, backgrounds, outlooks, religious beliefs, political points of view, intellectual skills, aspirations, and tastes. As a result, North America has always been a civilization of varied attitudes and opinions, which were occasionally filled with controversy, emotional feelings, expressions, and actions. Such controversies could serve as catalysts for progress, but they could also lead to prejudice, invalid generalizations, and half-truths. This presents a challenge, which appears endemic to liberal democracies. Its principled commitment to equal representation of all requires that citizens with different cultural identities, often based on ethnicity, race, gender, or religion, be recognized as equals in the way they are treated in politics or in the way their children are educated in public schools. Thus, liberal democracies must account for and recognize such particular identities. But the challenge endemic to liberal democracies is the necessity to also focus upon the interests, which serve to unify it. Its survival depends upon the existence of a set of commonly held ideals, which are transmitted from one generation to the next.

In Creating Citizens: Political Education and Liberal Democracy Professor Eamonn Callan set himself the task of addressing this crucial challenge within the context of political debate about education. The challenge of education in a liberal democratic state, Callan argues, is to effectively transmit the common democratic ideals, habits, and pattern of thought across generations, while remaining open and hospitable to a diversity of such ideals, habits, and patterns of thought. The challenge is further enhanced by the recognition that the controversy generated by such diversity could serve as a threat to the continued existence of such ideals. Should public education not recognize our particular identities, but only our more universally shared interests in civil and political liberties, income, wealth, health care, and education? Apart from ceding each of us the same rights as all other citizens, what does respecting people as equals entail? In what sense should our specific identities as men or women, African-Americans, Mexican-American, Asian-American, English-Canadian, French-Canadian, Christian, Jew, or Muslim publicly matter?

Callan opens the inquiry by introducing us to a "quick thought experiment". We are asked to imagine a society that is enviably wealthy and peaceful. It mani-

Paidensis 13:1, 2000 
fests all of the particular rights we have come to expect of a liberal democracy freedom of expression, equality before the courts, etc.. But its citizens suffer from voter apathy leading to limited political coverage by the media. This appears to result from a kind of sameness among political elites leaving the populace to believe that essentially nothing separates one party from another. Freedom of speech has been rendered insignificant because speech is no longer seen as a tool to defend a unique position on matters of the day. Dialogue and debate on matters of importance are limited, Callan continues, because the populace are either indifferent to such questions or are so rigid in their thinking that dialogue with those who are not of a like mind is thought to be repellent or futile. In what Callan calls his "Brave New World," which he agrees, is quite unimaginative, much religious, racial and ethnic diversity continues to exist. But as far as possible contact with those who are different is avoided, in spite of their legal rights being respected, because they are despised. When inevitable transactions across cultural divisions occur, everyone attempts to exploit benefit from, or cause harm to, the other within the limits of the law.

If you find Callan's description of his "Brave New World" somewhat appalling and poised for collapse it may be because of what he offers as the absence of a shared public morality that once enlivened its institutions. The point of his thought experiment, then, is to highlight the common ideal of liberal democracy. Thus, Callan contends that

to believe in liberal democracy is to believe in free and equal citizenship. Part of what that demands of us is the development of public institutions that function in ways we can justify on the basis of that ideal, and much of our politics is about how well we have succeeded or how badly we have failed in that project (p. 2).

Callan's "Brave New World" loses its public virtue, its shared way of public life. But it also presents us with a dilemma for it is the self-same shared way of public life, which requires a respect for differences. The formal education received by citizens in a liberal democracy must both prepare them in ways that will insure such public virtue while at the same time encouraging respect for differences. "If a theoretically-informed view of civic education is to be morally defensible", Callan argues,

it must do more than tell it what our children should learn in order to become good citizens; it must also affirm the importance of respecting the many different ways of life that individuals permissibly choose within the framework of free institutions, even when those differences divide them at the deepest levels of identity (p. 12).

The challenge for civic education, then, is to establish a common public virtue in the midst of a respect for differences. 
Callan's profound insights force us to confront one of the fundamental questions underlying education in a liberal democratic state. The dilemma Callan places before us is whether it is possible to pursue coherent, reasonable educational policies without succumbing to an elitist dogmatism encouraged by unity on the one hand, or giving in to the radical subjectivism encouraged by diversity on the other hand. An emphasis on a unified public virtue in educational policies and practices, posing as the deliverance of objective reason, often mask cultural discrimination and class bias. A focus on disciplines and instructional techniques that do not acknowledge the experiences, insights, or values grounded cultural, gender, or religious differences can have a dehumanizing influence on students. Such policies and practices are deserving of our critical scorn. But does such acknowledgement require whim as a substitute for a standard compulsory curriculum? After spending much of the first half of his inquiry establishing the nature of the good citizen in the liberal democratic state through an analysis of such concepts as judgement, autonomy, justice, value, choice, integrity, trust, and reason, all within the context of pluralism, Callan goes on to confront the dilemma before us and address its implications to education and schooling.

Is our focus to be on common schooling or separate schooling? Any attempt to address one horn of the dilemma is to risk being mauled by the other. Callan's strategy in addressing the dilemma is to take his lead from John Dewey's visionary idea of "an education for all that ennobles the common school" (p. 163). The task he sets himself is one of establishing a "suitably rich and inspiring view of a shared educational venture that would inform common schooling in a free society" ( $p$. 163). Callan's hope is to avoid being mauled by either horn of the dilemma by stepping between them. Thus, an argument is developed for common schooling that is "sensitive to considerations supporting the acceptability, even the desirability, of some kinds of separate schooling" (p. 163).

How can a diverse society educate its members for democracy? Callan identifies contemporary controversies about common schooling which turn on the clash of these two apparently competing educational aims: securing common public virtues and respecting cultural differences. Callan describes two responses that fail to do justice to both aims. One response, what Callan calls "Minimalist Common Education", sets the project of civic unity against the tendencies of cultural diversity. "Minimalist Common Education", as I understand Callan, views the very aim of representing or respecting differences in public institutions as misguided. An important strand of liberal democracy requires us to recognize that our freedom and equality as citizens refer only to our common characteristics. The focus must be 
upon our common needs, regardless of our particular cultural identities, for primary goods such as income, health care, religious freedom, freedom of speech, the press, and association, due process, the right to vote, and hold public office. These are interests shared by all regardless of race, religion, ethnicity, or gender. Therefore a "Minimalist Common Education" need not - indeed should not - strive to recognize our particular cultural identities in treating us as free and equal citizens.

The second response puts cultural diversity above the claims of civic education. Callan refers to this as the "Separatist Argument" (p. 167). The "Separatist" position suggests that people require a secure cultural context from which meaning and guidance is derived which serve to direct their life choices. Thus, a liberal democracy is obligated to help "cleavage" groups (self-identified groups who see themselves in some competition or conflict with other groups) preserve their culture against intrusions by a dominant culture.

Callan steps between the horns of the dilemma by grounding his argument in a view of justice as reasonableness (p. 175). Reasonableness is viewed as the prime virtue of citizenship for a free people. Such reasonableness, Callan argues, requires reciprocity. That is, "the reasonable citizen is disposed to propose fair terms of cooperation to others, to settle differences in mutually acceptable ways, and to abide by agreed terms of cooperation so long as others are prepared to do likewise" (p. 175). Such reasonableness as a political virtue is viewed as acceptable on both ends of the divide because it "requires us to care about something we can only do together" (p. 175). But in doing it together it "does no violence to the differences that divide us after we have reasoned about them as best we can". In the midst of the diversity the hope (through reasonableness) is to secure an identification with a particular political community as a setting for the realization of justice.

Identification makes the flourishing of the community a constituent of our own good, and because liberal patriots think their community's flourishing depends on its justice, conflict is mitigated between the rational pursuit of good and reasonable deference to the claims of others (p. 175).

Callan's approach to the realization of justice and the mitigation of conflict through reasonableness appears to be a viable alternative to what has come to be known as the "Iron Law of Ethnicity". According to this "law", where there is ethnic difference there will be ethnic conflict. The internal dynamics of "cleavage" group existence, if not human nature itself, are presumed to make ethnic conflict inevitable. One widely held view assumes, since a sense of "we" presupposes a sense of "they," it follows that ethnocentrism, prejudice, and conflict are natural byproducts of group identity and belonging (Allport, 1958). Admittedly, there is a great deal of superficial evidence to give credence to such a theory. The ideal of a

Paideusis 13:1, 2000 
plural society, where ethnic groups live in cooperation, harmony, and mutual respect, has proved a most elusive one. However, the force of Callan's argument is to allow us to recognize that it is possibly doubtful that the connection between ethnic difference and conflict is as automatic or as inevitable as is commonly supposed. We are forced to consider that if there is an iron law of ethnicity, its existence depends upon a hierarchy of power, wealth, and status that renders conflict inescapable. However, where there is social, economic, and political justice grounded in a reasonable deference to the claims of others ethnic conflict, when it occurs, tends to be at a low level and rarely spills over into violence.

Thus, the reasonableness of the good citizen in a liberal democracy requires an appreciation of "a multiplicity of perspectives" on any topic demanding judgement. Such reasonableness is best developed, Callan continues, within "dialogical contexts that straddle our social cleavages" (p. 177). This becomes the dialogical task of common education. The dialogical task requires a democratic environment. The dialogic approach to common education and schooling also requires that its participants be respected as rational agents, who are capable of reflective, critical assessment of their cultural assumptions and beliefs in light of evidence and logical considerations. This is considered by Mulvaney as the

nursery of the democratic ideal, where teacher and student share a crossgenerational issue of profound human significance, suggest alternative formulations of the question, and hint at possible answers, in a climate of respect and toleration (1992, p. 93).

Dialogue within a diverse educational context allows, and even forces, us to seek meaning and understanding in a variety of ways, and from a multiple of viewpoints. The student in such an environment develops the disposition to approach differences in a healthy and mature manner. Eamonn Callan's very powerful work serves this cause by providing a concept of political education that satisfies the demands of a democratic society with its fundamental beliefs and virtues. This was accomplished while also honoring the diversity that gives it strength and power. Such honor requires a tolerance to ways of life that possibly conflict with those demands. We are grateful to Callan for reminding us that it is through the development of reasonableness within the context of dialogic education that the next generation will be prepared socially and intellectually to engage in the necessary questioning and judging that is vital to the existence of a liberal democratic state. For a liberal democracy to flourish there is the demand that its citizens exist in a more reasonable and just manner. The ideas of Creating Citizens: Political Education and Liberal Democracy, taken seriously and acted upon, are to be taken as a valuable contribution in that regard.

Paideusis 13:1, 2000 


\section{References}

Allport, Gordon W. The Nature of Prejudice. New York: Anchor, 1958.

Callan, Eamonn. Creating Citizens: Political Education and Liberal Democracy. Oxford: Clarendon Press, 1997.

Mulvaney, Robert J. "Conversation, Dialogue, and Dialectic: A Response To Paul Bitting" in Creating a Multicultural Education Conversation, Joseph Congleton, ed. Proceedings of South Atlantic Philosophy of Education Society, 1992. 